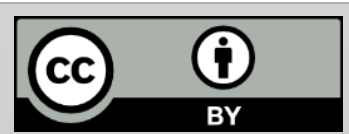

Copyright notice: This article is issued under the terms of the Creative Commons Attribution License, which permits use and redistribution of the work provided that the original author and source are credited.

You must give appropriate credit (author attribution), provide a link to the license, and indicate if changes were made. You may do so in any reasonable manner, but not in any way that suggests the licensor endorses you or your use. You may not apply legal terms or technological measures that legally restrict others from doing anything the license permits.

https://creativecommons .org/licenses/by/4.0/

\section{Is there an I in Impact? Considering the two-way process of public engagement.}

\section{Isabelle Heyerick}

Institute of Advanced Study and Centre of Applied Linguistics, University of Warwick, UK and Faculty of Arts, KU Leuven, Belgium

Correspondence: isabelle.heyerick@ac.uk.warwick

Twitter: @।Heyerick

\begin{abstract}
This article is a critical reflection on public engagement and the concept of impact in UK research institutions, based on a recent experience. The UK impact agenda, driven by the Research Excellence Framework (REF)i, requires researchers to engage with the public in order to potentially have an impact on society. This, I argue, constitutes the implicit directionality of impact as a one-way process. Recently, I provided a workshop for Flemish Sign Language (VGT) interpreters entitled 'I interpret, therefore I $a^{\prime}$ ' at the Faculty of Arts of the KU Leuven (Antwerp, Belgium). The aim of the workshop, in line with the impact agenda, was to increase participants' awareness about the interpreting process and change their perception of how an interpreter's personal beliefs potentially influence his/her linguistic choices. However, interacting with the participants also had an impact on my current research design and me as a researcher. This particular experience led me to reconsider the implicit idea of impact as a one-way process. In what follows I argue that, impact can and - in my opinion - should be a two-way process, encouraging interaction with the public in order to have a valuable impact on society, research and the researcher.
\end{abstract}

Keywords: REF; impact; public engagement; critical reflection; sign language; research design

\section{Impact in UK Academia}

As a new and European scholar at the University of Warwick I have been introduced to the UK's 'impact agenda' as part of the REF, an evaluation system used to assess the quality of research carried out in UK higher education. The outcomes of the evaluation are used to inform the allocation of public funding for universities' research. One criterion of evaluation is the impact academic research has on the larger (i.e. nonacademic) public. 
The UK Research and Innovation (UKRI) body distinguishes between (1) academic impact and (2) economic and societal impact. Defining the former as:

The demonstrable contribution that excellent research makes to academic advances, across and within disciplines, including significant advances in understanding, methods, theory and application. (UKRI, 2019a)

The latter refers to:

The demonstrable contribution that excellent research makes to society and the economy. Economic and societal impacts embrace all the extremely diverse ways in which research-related knowledge and skills benefit individuals, organisations and nations (...) (ibid)

UKRI also makes a distinction between (1) economic impact and (2) societal and cultural impact (UKRI, 2019b \& c). The first type is delivered, whereas the second one is created. Ultimately, it is their vision to maximise the impact of public investment in research. In similar fashion, the mission states that taxpayers' money will be invested wisely in a way that generates impact for citizens (UKRI, 2019d).

Whereas the UKRI and the former Research Councils UK emphasise the benefits of engaging with the public and potential impact for researchers (RCUK, 2010), these are not explicitly addressed by the University of Warwick, where I am currently a research fellow. The university seems to mainly focus on how research can bring about change in society, highlighting the economic and societal dimension of impact and putting lesser emphasis on academic impact. The university's webpage clarifies that 'impact is a dynamic concept that is evolving' (Warwick, 2019) and that they take impact to mean:

"...the identifiable and evidenced contribution made by universities to the economy and society." (ibid)

It goes on to say that an effective and efficient two-way relationship with stakeholders is required in order to achieve the potential impact of research. However, the university's webpage does not elaborate on what this relationship entails or how it affects both parties.

The fact that the governmental institutions and the university primarily address impact as academia's contribution to society made me (re)consider impact as a two-way process. Not only acknowledging how research can change society, but also regard how the non-academic audience can have an impact on research? My recent experience engaging as a researcher with a non-academic public during an impact activity reinforced this idea. 
There are several identifiable benefits of public engagement, one of the ways to obtain impact, for researchers. As mentioned, some of the advantages have been outlined in a Research Councils UK brochure What's in it for me? (RCUK, 2010). The brochure primarily focuses on how engaging in impact activities will enhance a researcher's career by raising his/her personal profile and improving specific skills such as communication and influencing. However, when I argue that impact should be approached as a two-way process, I suggest that academia should not only ask what research can do for the public, but also what the public can do for research.

There are various ways to adopt a bidirectional philosophy on impact in different stages of a research project. A research idea can be informed or even proposed by the general public, which flags a certain issue that warrants academic attention. This can result in a community-based participatory research project where the non-academic group is not limited to being a beneficiary of the research but is treated as an equal partner, informing and forming the project. Another possibility lies in close consultation with the public at the conception stage of a research idea. Listening to, involving and interacting with a non-academic audience can improve the quality of research questions and/or hypothesis. The public views might offer fresh perspectives on the topic and allow the researcher to take on board ideas he/she might not have considered. Similarly, consulting the general public can allow to tease out research ideas and assess the feasibility of a project. At the conclusion of a research project it might be valuable to present research results to the general public and engage them in the interpretation of the findings. Not only can this kind of interaction help to improve the quality of the research and ground it within society, it potentially feedbacks into new research questions. Engaging with the public can be a springboard for new research that from the onset is informed and supported by the public. Ultimately, these suggestions to ensure the two-way process of impact will increase the impact the research has on society, research and the researcher.

\section{Impact Activities}

As mentioned, one way to achieve impact is through public engagement, i.e. communicating research to a non-academic audience. However, this in itself does not constitute as impact as defined by the University of Warwick. It is not sufficient to talk about or share insights based on your research with non-specialists. In order to achieve impact, the activity has to have made a demonstrable change. Generally this change is measured through an evaluation, establishing whether attendees' knowledge has shifted. And if so, whether this will influence future behaviour. 
One example of a valid impact activity is giving a research-informed workshop to a non-academic audience. In May 2019 I was invited to provide a workshop at the $10^{\text {th }}$ anniversary of the association of VGT (Flemish Sign Language) interpreters (BVGT)ii. The event was held at the KU Leuven, Faculty of Arts in Antwerp (Belgium) and convened VGT interpreters, interpreter educators, deaf and hearing interpreter consumers, and leaders from the Deaf and interpreting community. I provided an interactive workshop based on my PhD and current postdoctoral research. My PhD project describes which linguistic interpreting strategies VGT interpreters use when interpreting from Dutch into Flemish Sign Language and also explores the interpreters'

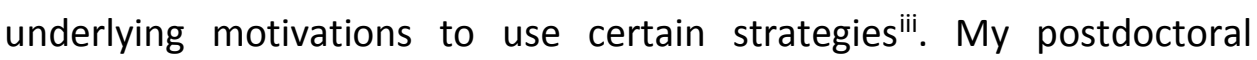
project examines if and how ideologies on deafness, disability, and language influence linguistic decisions signed language interpreters make ${ }^{\text {iv }}$.

\section{Workshop I interpret, therefore I am: The set up and aims}

The workshop ran twice and per session maximum fifteen participants were allowed. Both sessions were conducted in Flemish Sign Language (VGT) since that was the shared language between the participants (deaf and hearing) and myself.

In the spirit of public engagement and the impact agenda, I wanted to inform the audience about and possibly change their understanding of the interpreting process and how their own beliefs can potentially influence that process. At the same time, I saw the workshop as an opportunity to tease out some preliminary research findings and ideas concerning my postdoctoral study. I aimed to (1) increase the participants' awareness of the strategic nature of interpreting, (2) expand their knowledge of linguistic interpreting strategies, (3) spark apprehension of how personal beliefs can influence the linguistic decisions interpreters make, and (4) test preliminary findings and a research hypothesis.

The workshop consisted of four parts: (1) an icebreaker, (2) a theoretical introduction to interpreting as a strategic process, (3) a hands-on and reflective exercise, and (4) a creative conclusion.

The icebreaker was a short activity introducing the topic. The participants were divided in groups and handed a card on which the word interpreter was printed. They had ten seconds to perform a tableau vivant. This encouraged the participants to quickly decide on what interpreter means to them. Since all of the attendees knew VGT and this task allowed nonverbal expression, many of the groups used the sign for interpreter ${ }^{v}$ in 
their tableau vivant. One group presented their understanding of the concept as follows:

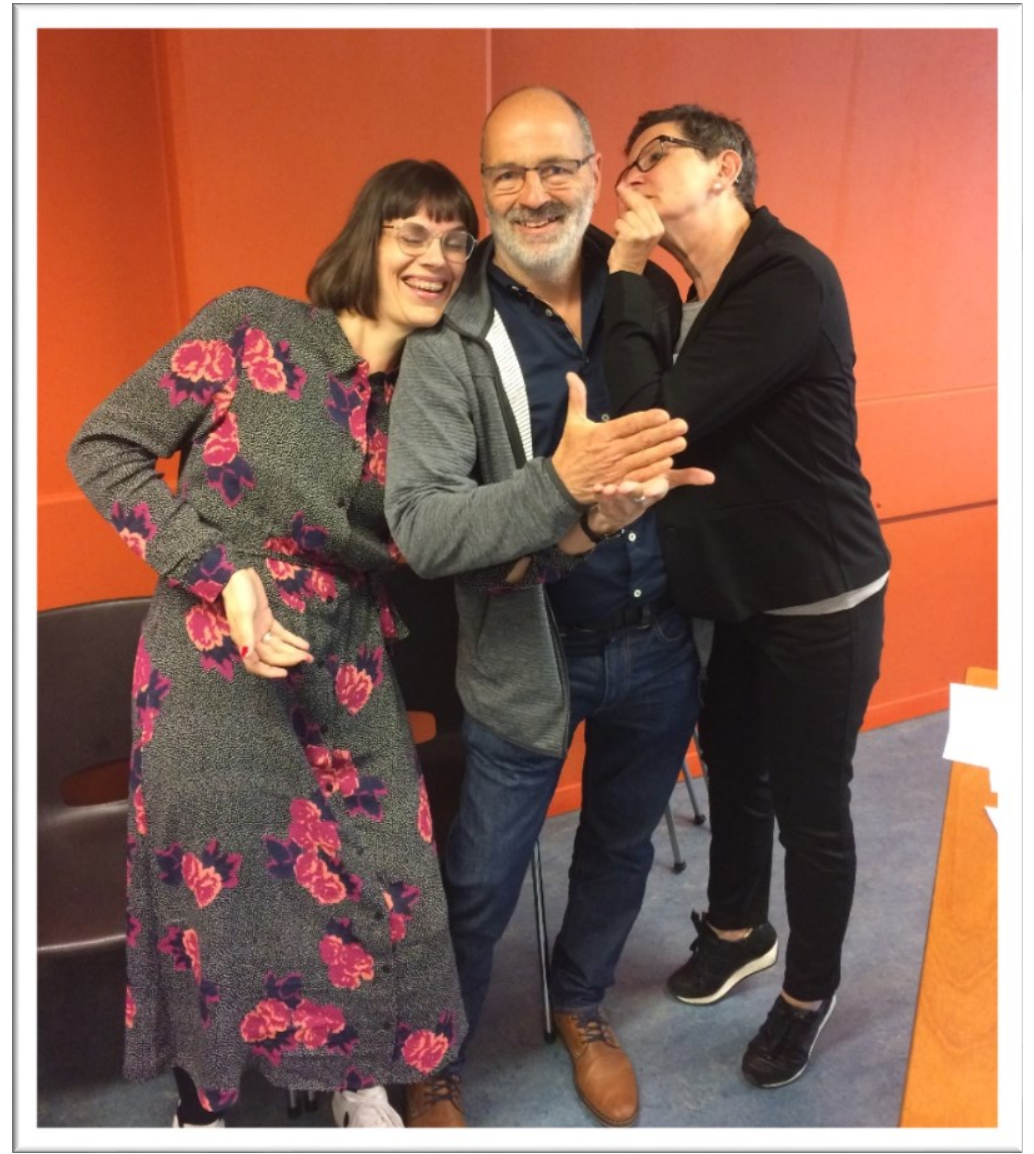

Figure 1: Tableau vivant of the concept 'interpreter'. Source: author's personal image.

In the middle you can see the man's right hand and the woman in the floral dress's left hand jointly producing the sign for interpreter. The woman's right hand symbolises signed language whereas the other woman is demonstrating spoken language. This particular scene captures several characteristics of the interpreter; (1) being in between two people and languages, (2) the spoken and signed working modalities, and (3) collaboration. The tableau vivant allowed the participants to discover their view of interpreter in a creative and playful manner.

The second part of the workshop was a theoretical introduction to linguistic interpreting strategies, the results of my PhD study, and the idea of interpreting as a strategic process. In order to ensure that all participants departed from the same knowledge base, I presented an overview of (1) the Effort Models (Gile, 1995 (revised 2009); 2018), (2) the sociolinguistic model of sign language interpreting (Cokely, 1992), and (3) interpreting as a goal-oriented process (Pöchhacker, 2004). In his models, Gile foregrounds the cognitive and psycholinguistic aspects of interpreting, whereas Cokely broadens the perspective by taking into 
account the sociolinguistic aspects of communication. The theoretical framework put forward by Pöchhaker seeks to unite both models and gives significance to interpreting as a cognitive an interactive discourse information processing activity.

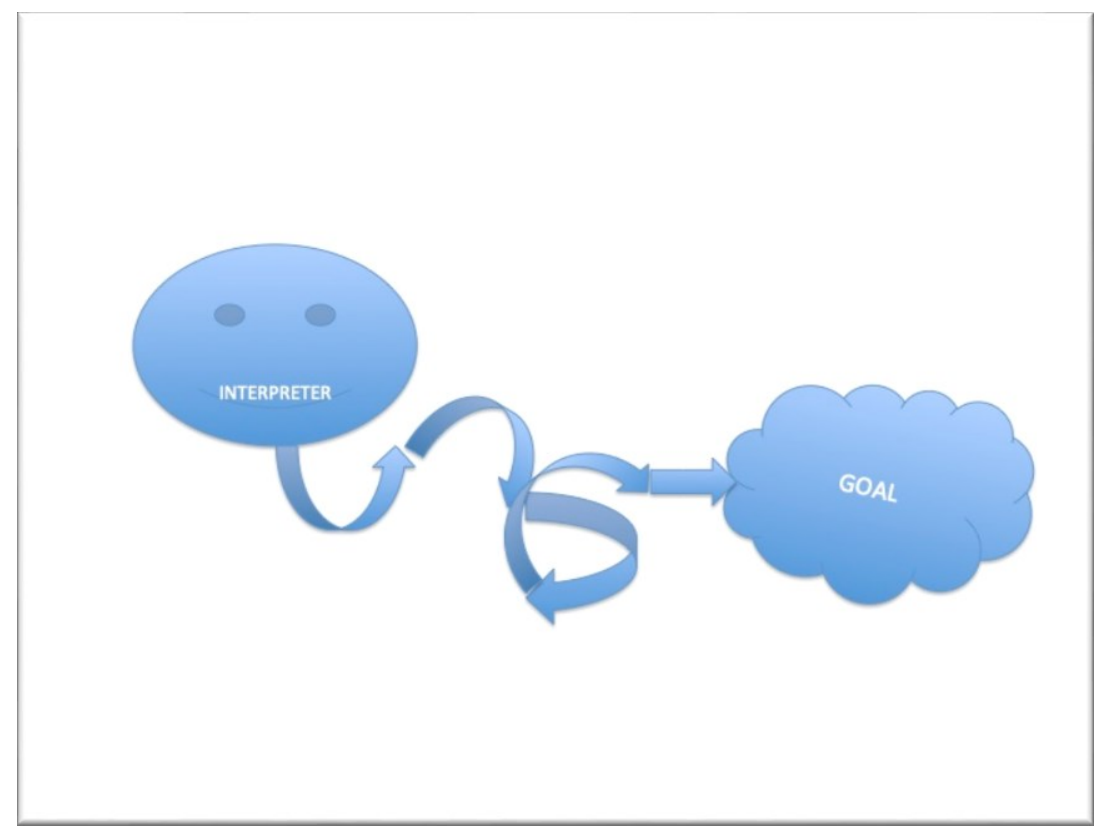

Figure 2: Interpreting as a goal-oriented process. Source: author's personal image.

I encouraged the audience to reflect about their understanding of the interpreting process by presenting the following yes - no-statements:

1. interpreting is a cognitive process

2. interpreting is a goal oriented process

3. interpreters make linguistic decisions

4. interpreting is strategic in nature

The participants were invited to express their agreement or disagreement by a show of hand and - if not everyone held the same view - to clarify their position.

Subsequently, I presented an overview of linguistic interpreting strategies and of motivations for using these strategies based on the results of my PhD research (Heyerick, forthcoming).

The third part of the session allowed the participants to put theory into practice. In groups of maximum three, each interpreted a Dutch text ${ }^{\mathrm{vi}}$ (containing statements on deafness, signed languages and interpreting) into Flemish Sign Language while the other person(s) observed the interpretation and wrote down the used strategies. After ten minutes, the observer(s) and interpreter discussed the strategies and why the 
interpreter used them. This was repeated until each participant interpreted a fragment and discussed the strategies. This approach allowed for participants to (1) observe and identify strategies, (2) talk about strategies, (3) think about why a certain strategy is used, (4) explore what motivates certain choices, and (5) have a peer discussion. At the same time it allowed me to (1) assess the participants' knowledge and understanding of linguistic interpreting strategies, (2) interpret the results of my PhD study, (3) evaluate if the methodology works and can be reiterated, and (4) confirm or contradict preliminary findings of my postdoctoral project.

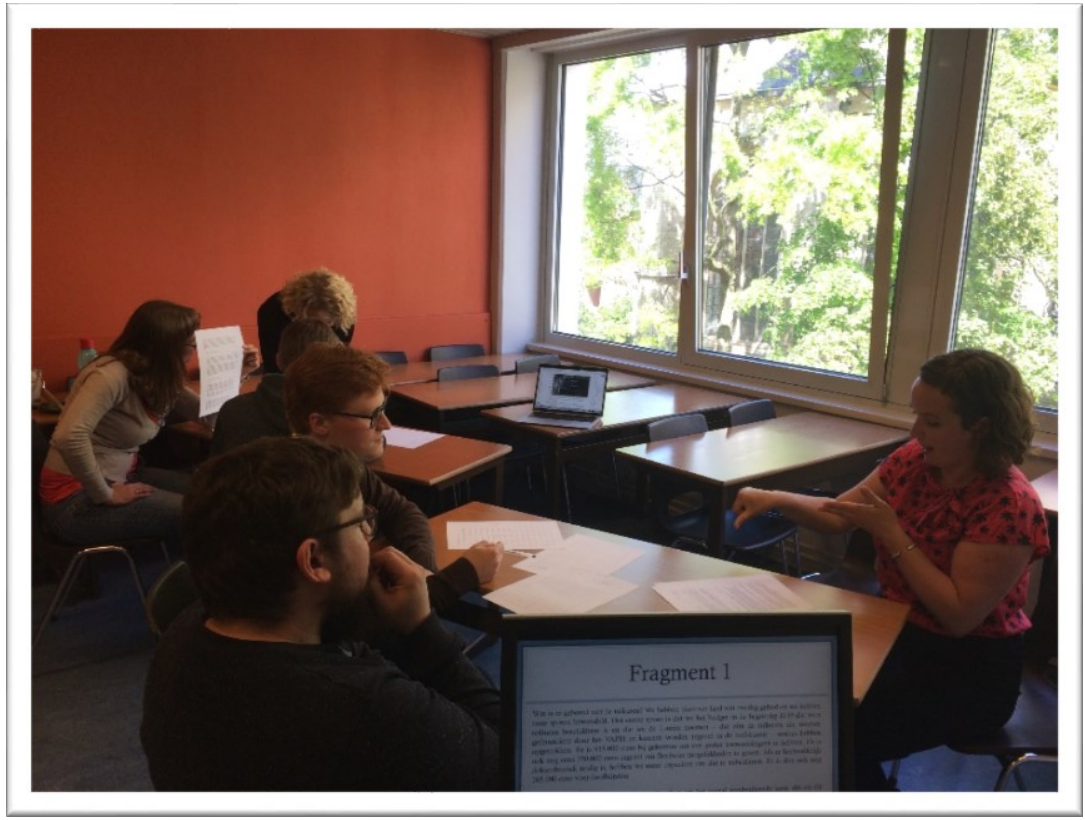

Figure 3: The Interpreter/Observer Task. Source: author's personal image.

The workshop was concluded by a brief group discussion after which I asked the participants to draw their self-portrait as an interpreter. Based on their experience of the interpreting task and the discussions, I wanted them to visually represent how this (re)shaped their image of ' $I$, the interpreter'. 


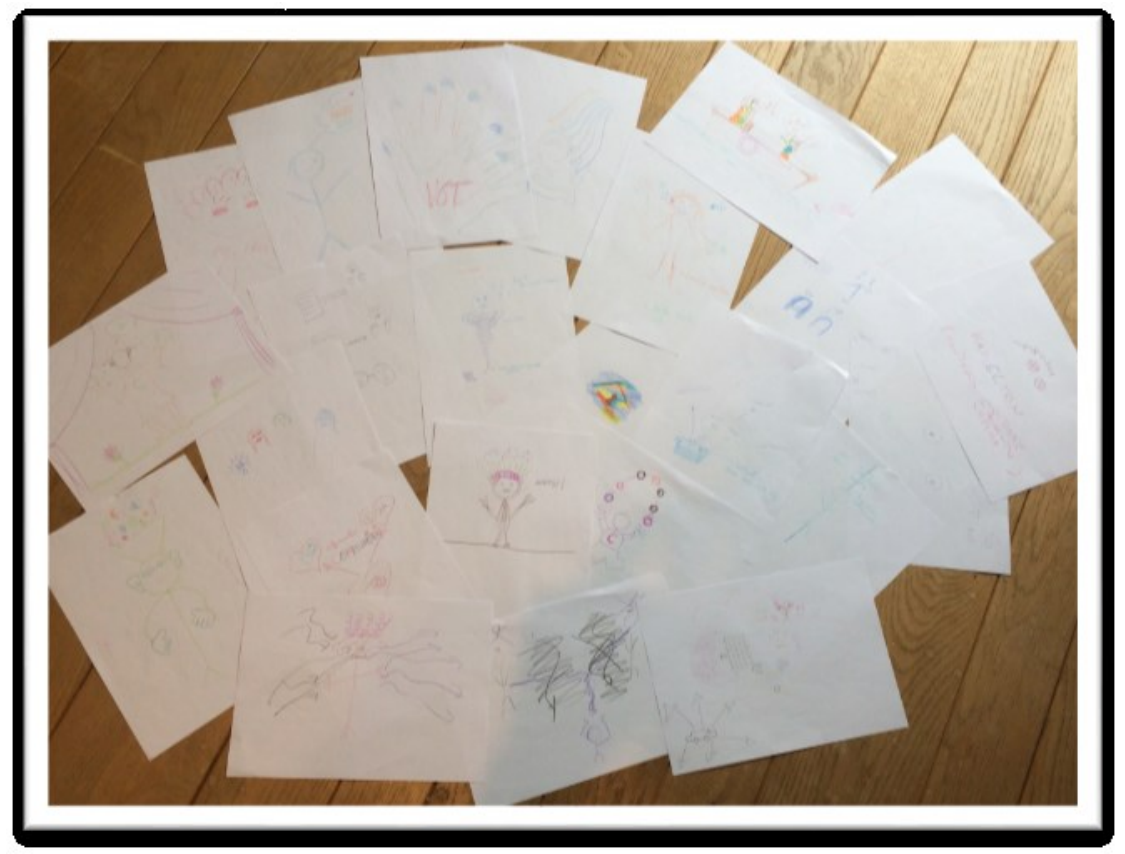

Figure 4: Participants' Self-Portraits as 'interpreter'. Source: author's personal image.

\section{Workshop I interpret, therefore I am: The impact}

One of the requirements of impact, as it is conceptualised within the REF, is that it needs to be identifiable and evidenced. Keeping this in mind, participants were invited to fill out an online evaluation form a couple of days following the workshop. Out of twenty-nine participants only seven did so. Along with general feedback, people were asked if the workshop had provided them with new insights and if so, which ones. Five out of the seven respondents indicated that this was the case. Additionally, the form also inquired whether the attendees learnt something during the session that they can apply in their professional or personal life. To this question three persons responded affirmative. During and after the workshop participants also shared that they had gained new insights about the interpreting process and in particular about how their beliefs about interpreting and language inform the strategic decisions they make. Some of them referred to the session as an 'Aha-experience'. During break-time conversations participants expressed that they particularly appreciated the theoretical discussion, the peer-support, the open and collaborative feedback and the time and space they were offered to think about interpreting. They felt that these aspects lack in their current professional development. Many of them requested a full day repeat of this workshop, which was also mentioned in the feedback forms (five out of seven respondents). These responses show that the workshop allowed me to engage with and potentially have an impact on my audience. 
As a researcher, I felt challenged and validated by the event and the interaction with the participants. First of all, since some aspects of the theoretical framework I presented were unexpectedly challenged I had to reconsider what I assumed to be common knowledge. I believed that the fact that an interpreter is a participant in the interpreted interaction and has agency is accepted knowledge. However, participants' statements such as 'as an interpreter I do not have a voice', or 'I only interpret', and 'I do not have a goal as an interpreter' challenged this assumption. Some attendees subscribed to the, in academia out-dated and rejected, idea of the interpreter as a conduit, a neutral translating machine. This in turn made me question the actual impact of impact. The conduit model in interpreting stems from the 1980s and has been overturned since the sociolinguistic shift in interpreting studies in the 1990s. The 'myth of neutrality' has been addressed and unveiled by scholars since the seminal work of Metzger (1999). Bearing in mind that most interpreting studies' scholars are interpreters themselves and interpreting educators, some participants' comments reminded me that there is nonetheless still a substantial gap between academia and the community of practitioners. This realisation reinforced the idea that engaging with non-academic audiences is necessary and that it is indeed a task of academia to do so.

At the same time I was able to present and discuss the results of my PhD research, which resulted in fresh perspectives on what constitutes as a linguistic interpreting strategy. The interaction also enhanced my understanding of some inductive theoretical ideas. Additionally, I was able to test the methodology for my postdoctoral study and, based on the participants' feedback, implement some changes. Finally, I could tease out a research idea and approach, which was validated by the attendees' confirmation of preliminary findings.

On the one hand the workshop increased the audience's awareness and made them reconsider their concept of interpreting. On the other hand engaging with the public also challenged and validated the research. This, in my opinion, shows how impact can -and should- be a two-way process.

\section{Conclusion}

Whereas the institutional discourse surrounding public engagement and impact mainly stresses the change research can initiate in non-academic society, this personal experience made me realise that impact can and should be a two-way process. On the one hand the workshop reported on in this paper, intended to engage with and potentially impact its audience. However, at the same time I hoped that the interaction would enhance my understanding of some inductive theoretical ideas. In the end, this particular activity made an impact not only on the participants, 
but also on my research and myself as an academic, demonstrating that indeed an effective and efficient two-way relationship with stakeholders is required in order to achieve the full potential of impact.

\section{Acknowledgments}

I would like to acknowledge Prof. Liddicoat for his comments on earlier drafts.

\section{List of Images}

Figure 1: Tableau vivant of the concept 'interpreter'. Source: Author's personal collection.

Figure 2: Interpreting as a goal-oriented process. Source: Author's personal collection.

Figure 3: The Interpreter/Observer Task. Source: Author's personal collection.

Figure 4: Participants' Self-Portraits as 'interpreter'. Source: Author's personal collection.

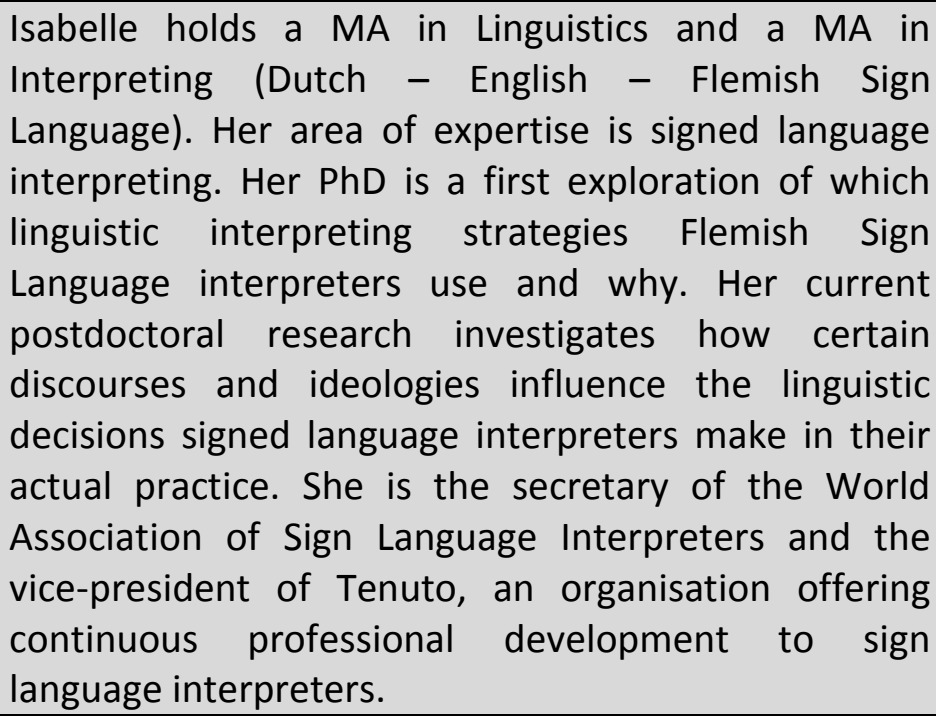




\section{References}

Cokely, D. (1992). Interpretation: A sociolinguistic model. Burtonsville, MD: Linstok Press.

Gile, D. (1995, revised 2009). Basic Concepts and Models for Interpreter and Translator Training. Philadelphia: John Benjamins.

Gile, D. (2018). The Effort Models and Gravitational Model. Clarifications and update. https://www.cirinandgile.com/powerpoint/The-EffortModels-and-Gravitational-Model-Clarifications-and-update.pdf [Accessed 10th September2019].

Heyerick, I. (forthcoming). A descriptive study of linguistic interpreting strategies used by Flemish Sign Language (VGT) interpreters.

Understanding the what, how, and why. Doctoral dissertation. KU Leuven, Antwerp, Belgium.

Metzger, M. (1999). Sign language interpreting: Deconstructing the myth of neutrality. Washington, D.C: Gallaudet University Press.

Pöchhacker, F. (2004). Introducing Interpreting Studies. Routledge.

RCUK, 2010. What's in it for me? The benefits of public engagement for researchers. Swindon: Research Councils UK.

https://www.ukri.org/files/legacy/scisoc/rcukbenefitsofpe-pdf/

[Accessed 28 ${ }^{\text {th }}$ June 2019].

UKRI, 2019a. Pathways to Impact. Swindon: UK Research \& Innovation. https://www.ukri.org/innovation/excellence-with-impact/pathways-toimpact/ [Accessed June 27 ${ }^{\text {th }}$ 2019].

UKRI, 2019b. Delivering Economic Impact. Swindon: UK Research \& Innovation. https://www.ukri.org/about-us/strategic-

prospectus/delivering-economic-impact/ [Accessed $27^{\text {th }}$ June 2019].

UKRI, 2019c. Creating Social and Cultural Impact. Swindon: UK Research \& Innovation. https://www.ukri.org/about-us/strategicprospectus/creating-social-and-cultural-impact/ [Accessed June $27^{\text {th }}$ 2019].

UKRI, 2019d. Vision, Mission and Values. Swindon: UK Research \& Innovation. https://www.ukri.org/about-us/strategic-prospectus/visionmission-and-values/ [Accessed June $27^{\text {th }} 2019$ ].

Warwick, 2019. Impact. Coventry: University of Warwick. https://warwick.ac.uk/services/ris/impactinnovation/impact/ [Accessed June 27th 2019]. 


\section{To cite this article:}

Heyerick, I., 2019. Is there an I in Impact? Considering the two-way process of public engagement. Exchanges: The Interdisciplinary Research Journal, 7(1), 82-93. Retrieved from: http://doi.org/10.31273/eirj.v7i1.520.

\section{Endnotes}

\footnotetext{
i https://www.ref.ac.uk

ii Beroepsvereniging van Vlaamse Gebarentaal Tolken

iii https://strategicinterpreting.blog

iv https://warwick.ac.uk/fac/cross fac/ias/iaspeople/fellows/wirl

${ }^{v}$ http://gebaren.ugent.be/alfabet.php?id=18828

vi The selected text was a transcript of a Flemish Parliament hearing on the legal actions the Flemish Deaf Association (DoofVlaanderen) and several deaf individuals plan against the Flemish government with regard to VGT interpreting service provisions:

https://www.vlaamsparlement.be/plenairevergaderingen/1316591/verslag/1317540/persoon/bart-van-malderen, accessed July $2^{\text {nd }} 2019$
} 